\title{
AN EVALUATION OF THE EFFECT OF AGGREGATE TYPE ON HOT MIX ASPHALT PROPERTIES IN KURDISTAN REGION OF IRAQ
}

\author{
SHEYAN Alyousify* ${ }^{*}$ and SUNDIS M. S. TAHER ${ }^{* *}$ \\ * Dept. of Highways and Bridges Engineering, College of Engineering, Duhok Polytechnic University, \\ Kurdistan Region-Iraq \\ ** Dept. of Civil Engineering, College of Engineering, University of Duhok, Kurdistan Region-Iraq
}

(Received: September 12, 2021; Accepted for Publication: December 5, 2021)

\begin{abstract}
Hot mix asphalt (HMA) is a mixture that contains, approximately $95 \%$ by weight of aggregates. As a consequence the types of aggregates and their characteristics are of most significance in enhancing the durability of asphalt mixture worldwide. Accordingly the impact of aggregate type and gradation has been the focus of many researchers all over the world. In this investigation the effect of aggregate type on HMA in Kurdistan region/ Iraq were spotlighted. More precisely, in addition to gravel which is dominantly used in Kurdistan, crushed stone and limestone were the other types of aggregates that were concerned in the present work. The volumetric properties using Marshall Method of asphalt containing each of these aggregates were inspected. Moreover, the characteristics of aggregates that examined in this study were specific gravity and toughness (Los Angeles abrasion test). Experimental observations revealed that the toughness of gravel and crushed stone was higher than that of limestone as the L.A. abrasion for the latter was considerably higher than that of crushed stone and gravel. Crushed stone with $4.2 \%$ binder content resulted in an acceptable flow value according to Iraqi SORB/2003 as well as gravel mix of $4 \%$ binder content, while limestone with higher optimum binder content of $6 \%$ recorded a non-acceptable value of $4.4 \mathrm{~mm}$. The stability of limestone mix appeared to be higher by $36 \%$ and $50 \%$ than that for crushed stone and gravel mix, respectively.
\end{abstract}

KEYWORDS: Hot Mix Asphalt, Marshall Method, abrasion, gravel, limestone, crushed stone, stability.

\section{INTRODUCTION}

$\mathbf{O}^{-}$ ne of the most popular kinds of asphalt pavement design used in various countries worldwide is hot mix asphalt (HMA). Hot mix asphalt, is a diverse heterogeneous composite made up primarily of graded aggregate, asphalt mastic (i.e., includes asphalt binder, fine aggregate, and filler), and percent of air voids that are widely used for preparing the wearing course of asphaltic pavements(Dai, 2010). Despite the fact that there are many methods for HMA design including the Marshall, Superpave, and Hveem methods. The Marshall process is still used to design HMA mixes (Jitsangiam et al., 2013; Al-Humeidawi, 2016) . By volume, mineral aggregate; which includes coarse and fine particles in asphalt paving mixtures, makes up about $85 \%$ of HMA (Kalaitzaki et al., 2016). Thus, the properties of aggregate considerably influence on the asphalt performance (Prowell et al., 2005; Ahmed and
Attia, 2013). Aggregates ranging from $4.75 \mathrm{~mm}$ to $25.4 \mathrm{~mm}$ are considered coarse aggregates, while those less than $4.75 \mathrm{~mm}$ are fine aggregates, and filler size is less than $75 \mu \mathrm{m}$ according to Iraqi SORB (State Corporation for Roads and Bridges) (2003). Aggregate must be tough enough to withstand any activity that the pavement may undergo, which is represented by Los Angeles (L.A.) abrasion (ASTM C131-01, 2001; AASHTO T96, 2002). Despite its widespread usage, researchers and project consultants scored the LA abrasion test's predictive potential as only reasonable $(\mathrm{Wu}$ et al., 1998). Whereas good correlation with performance were found by more recent studies (Weyers et al., 2005; Williams and Cunningham, 2012). Recently some researchers have attempted to compare the use of different types of aggregates in HMA. A comparison study was carried out by Al-Saadi et al. (2011) between the using of White crushed gravel or rounded (WCG, WRG) and Black rounded gravel (BRG) 
which is considered as one of the most widely used types of aggregates in Iraq. Experimental observations displayed that WCG mix with $5 \%$ binder content increased the stability by $25 \%$ compared to BRG mix having a binder content of $4 \%$. In addition the flow of WCG found to be $2.2 \mathrm{~mm}$ which was less than that of WRG and BRG yielding $2.7 \mathrm{~mm}$ and $3 \mathrm{~mm}$, respectively. Ahmed and Attia (2013) investigated the Marshall properties of HMA utilizing different types of aggregates. They deduced that the flow of Basalt with open gradation (2C) was the highest, while Dolomite of coarse gradation (3A) recorded the lowest value of flow. Moreover, the Limestone with dense gradation (4C) gave the highest stability whereas the lowest value of stability was attained by Basalt of open gradation (2C). Furthermore, their results indicated that the lowest rutting was achieved by Dolomite. Mahmoud, (2014) evaluated the impact of aggregate type and gradation on HMA. She found that Limestone aggregate with a gradation of $4 \mathrm{C}$ had the greatest value of stability, whereas Basalt aggregate with a gradation of $2 \mathrm{C}$ had the lowest. The highest value of flow was found in a basalt mix of coarse gradation, while the lowest value was found in limestone of fine gradation. She further found that the coarse gradation of asphalt mixture has the greatest flow resistance, while the fine gradation has the most deformation. This implies that coarser gradations are predicted to outperform finer gradations.

Pandit et al. (2019) presented a research dealt with the effect of aggregate type on Marshall properties of HMA containing fly ash. Furthermore, the results showed that the mix contained limestone gives higher values of Marshall Stability and stiffness than that containing Basalt as an aggregate. Ahmed et al. (2014) investigated the effect of aggregate shape on the properties of HMA. They found that the use of rough crushed gravel increased the Marshall Stability, bulk density, Marshall Quotient (MQ) compared with the using of smooth crushed gravel. Whereas, a declined trends were found in VTM (the void in total mixture) and flow values when rough particles were used. Moreover, the use of rough aggregate gave the higher Indirect Tensile strength (ITS), stiffness values than smooth particles. They further concluded that using medium gradation aggregates gives the highest values of stability, VTM and MQ compared with the maximum and the minimum gradations.
Cui et al. (2014) presented a research involved the comparison of two basic aggregates, limestone and marble with two acidic granites. The outcomes showed that the basic aggregates (Limestone and marble) exhibited greater water resistance than acidic aggregates. Regarding the basic group Marble seemed to give a better water resistance than Limestone as a consequence of higher porosity of the former. The stripping and static creep behaviour of HMA were examined by AboQudais and Al-Shweily (2007). Their results showed that the type of aggregates affects remarkably on the stripping of HMA. The stripping resistance of unconditioned HMA asphalt prepared with limestone was higher than that of HMA asphalt prepared with basalt aggregate. When the HMA was subjected to conditioning, the effect was reversed. HMA stripping resistance was observed to have a good reverse association with the percentage of absorbed asphalt. Besides, they found that the gradation of aggregates has a great effect on stripping resistance as well. Additionally, the ability of adhesion work to represent the effect of aggregate type and gradation, as well as the type of asphalt on stripping resistance was discovered in their study. The effect of the kind of asphalt used to prepare the HMA on stripping resistance, however, was not detected.

Gravel stone has been the most type of coarse aggregates used in Kurdistan region of Iraq due to the reason of its availability and excellent strength properties. However, there are other stone types in Kurdistan that can be used as an alternative to gravel, namely: limestone and crushed stone (Sissakian, 2019).

The aim of the current study was to focus on the effect of aggregate type characteristics on the properties of HMA using Marshall method. Three types of aggregates were used namely, gravel, crushed stones and limestone from different locations of Kurdistan region of Iraq. More specifically, as gravel is the most commonly used in Kurdistan region as a HMA aggregate, hence, this study was seeking for other alternatives for gravel, viz. Limestone and crushed stone. Testing program covered conducting the Marshall tests for these three types of aggregates. Moreover, for the Marshall design, the toughness and specific gravity of aggregates are important factors to understand the effect of aggregate charecteristics on the asphalt mix properties. Thus, in this research the abrassion (L.A.) test and specific gravity test 
were also performed. The tests were done according to ASTM/2001 (American Society For Testing And Materials) and SORB/2003 specifications (State Corporation for Roads and Bridges) (SORB, 2003).

\section{MATERIALS AND METHODS}

\subsection{Materials}

2.1.1. Bitumen
The bitumen used in the present study was (40/50) grade bitumen from Kirkuk refinery obtained from a construction of the main highway that connects Zakho and Duhok cities, in Northern of Kurdistan region of Iraq. The properties of the bitumen were obtained by conducting the tests as shown in Table (1). All characteristics were conformed to SORB/2003 specifications.

Table (1): Physical properties of studied bitumen

\begin{tabular}{lcccc}
\hline Parameter & Value & Units & $\begin{array}{c}\text { S.O.R.B. } \\
\text { Specifications }\end{array}$ & Test \\
\hline $\begin{array}{l}\text { Penetration at } 25 \\
\text { C, } 0.1 \mathrm{~mm}\end{array}$ & 44 & $1 / 10 \mathrm{~mm}$ & $40-50$ & ASTM D5 \\
\hline $\begin{array}{l}\text { Ductility, }\left(25^{\circ} \mathrm{C},\right. \\
5 \mathrm{~cm} \text { min) }\end{array}$ & 160 & $\mathrm{~cm}$ & $>100$ & ASTM D113 \\
\hline $\begin{array}{l}\text { Softening point } \\
\text { (R+B) }\end{array}$ & 54 & ${ }^{\circ} \mathrm{C}$ & $50-60$ & ASTM D36 \\
\hline $\begin{array}{l}\text { Flash } \\
\text { (Cleveland point }\end{array}$ & 284 & ${ }^{\circ} \mathrm{C}$ & $>232$ & ASTM D92 \\
cup) & & & & \\
\hline $\begin{array}{l}\text { Specific gravity at } \\
25^{\circ} \mathrm{C} \text {. }\end{array}$ & 1.03 & & & ASTM D70 \\
\hline $\begin{array}{l}\text { Penetration at } 25 \\
\text { C, } 0.1 \text { mm after }\end{array}$ & 54.73 & $1 / 10 \mathrm{~mm}$ & $>53$ & ASTM D5 \\
$\begin{array}{l}\text { Rolling Thin film } \\
\text { oven test (RTFO) }\end{array}$ & & & & \\
\hline $\begin{array}{l}\text { Ductility, Cm } \\
\text { after Rolling Thin } \\
\text { film oven test }\end{array}$ & 30 & $\mathrm{~cm}$ & & ASTM D113 \\
\hline
\end{tabular}

\subsubsection{Aggregates}

Three types of aggregates from different locations of Kurdistan region were used in this study, namely: gravel stone from Tigris river deposit, limestone from a quarry in "SejeDuhok" with white colour, and crushed stone from a quarry in "Barzan-Erbil" with reddish colour, as shown in Fig. (1). The grading of gravel, limestone and crushed stone was complied with SORB/2003 specification, as shown in Fig. (2). The job mix formula for gravel was obtained from a construction of the main highway that connects Zakho and Duhok cities. Whereas the exact sieve weight gradation was used for limestone and crushed stone to obtain their gradation.

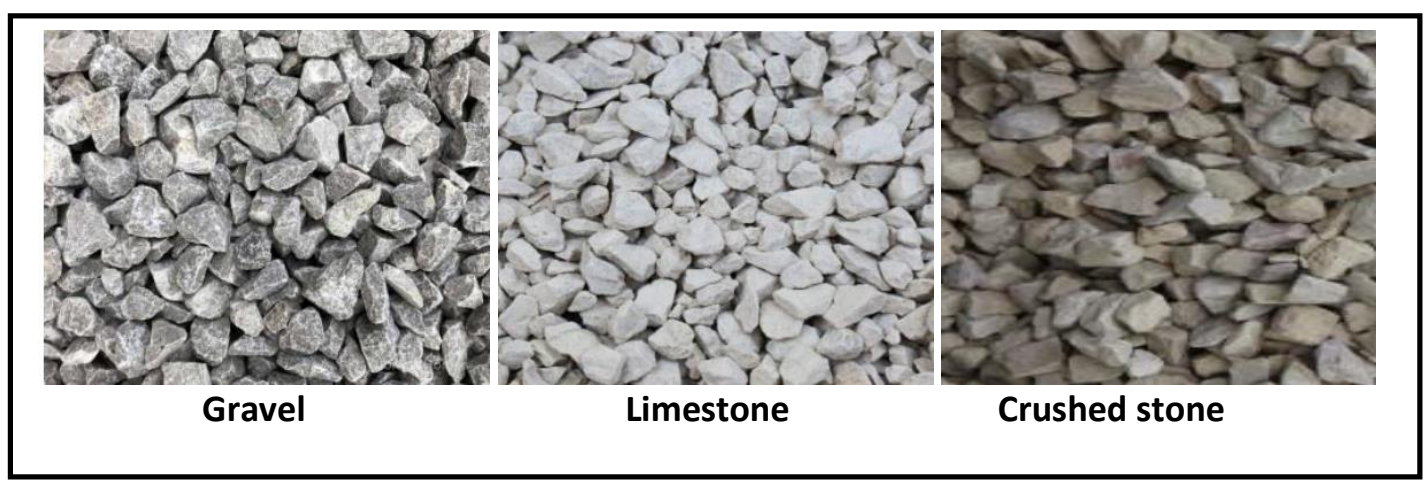

Fig. (1): Types of Aggregates 


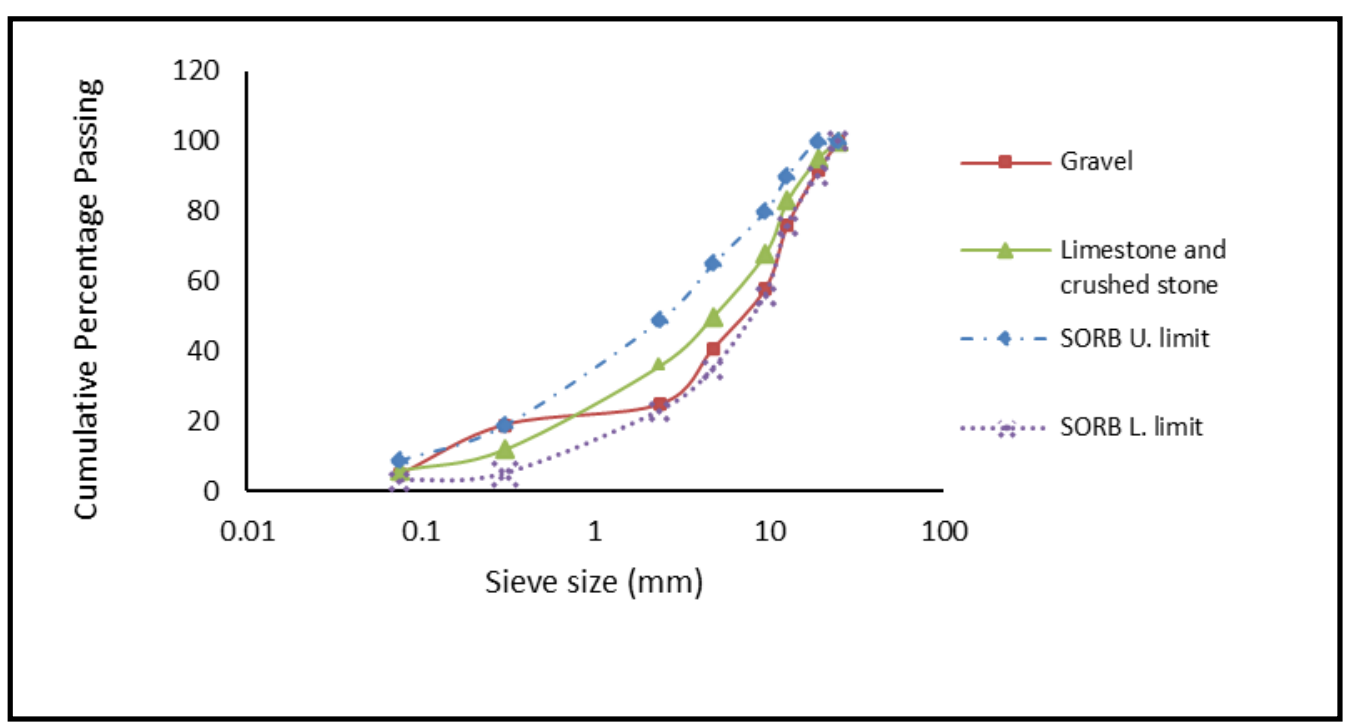

Fig. (2): Grading of aggregates

\subsubsection{Filler}

In this paper the filler used was a limestone dust which was provided from a quarry in SejeDuhok (Fig. (3)). Table (2) shows the physical properties of filler.

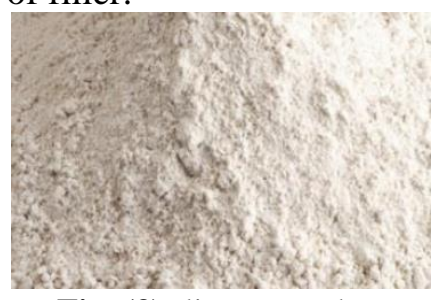

Fig. (3): limestone dust

Table (2): Physical properties of filler

\begin{tabular}{cc}
\hline Property & Limestone dust \\
\hline Passing sieve no. 200 & $95 \%$ \\
\hline Specific gravity & 2.7 \\
\hline
\end{tabular}

2.2. Preparation of samples and testing methods 2.2.1. Specific gravity and absorption

Coarse aggregate specific gravity was obtained by conducting Basket method

$\mathrm{A}=$ weight of dry aggregate in air

$\mathrm{B}=$ weight of saturated surface dry (SSD) aggregate in air

$\mathrm{C}=$ weight of saturated aggregate in water.

Bulk sp. Gr. (Gsb) = A/(B-C)

Actual sp. Gr. (Gsa) = A/(A-C)

Absorption\% $=(\mathrm{B}-\mathrm{A}) / \mathrm{A} \times 100$

Fine aggregate specific gravity was obtained by flask method:
$\mathrm{A}=$ weight of dry aggregate in air $(\mathrm{g})$.

$\mathrm{B}=$ weight of pycnometer filled with water to calibration mark, $(\mathrm{g})$.

$\mathrm{C}=$ Weight of pycnometer with aggregate and filled with water, $(\mathrm{g})$.

$\mathrm{W}=$ Weight of saturated surface dry aggregate in air, (g).

Bulk sp. Gr. $(\mathrm{Gsb})=\mathrm{A} /(\mathrm{B}+\mathrm{W}-\mathrm{C})$

Actual sp. Gr. (Gsa) = A/(A-C)

Absorption\% $=(\mathrm{B}-\mathrm{A}) / \mathrm{A} \times 100$

\subsubsection{Abrasion test (L.A.)}

Abrasion test was performed in compliance with AASHTO T96 (2002) to assess the aggregate's toughness. For this test, a $5000 \mathrm{~g}$ sample was taken from each aggregate that passes sieve $12.5 \mathrm{~mm}$. The sample of specified size was then placed in the abrasion drum (Fig. (4)) and 11 steel balls were placed within the drum, then the drum was rotated at 30-33 rpm. Thereafter the sample was removed and washed over sieve No. $12(1.7 \mathrm{~mm})$ then kept in an oven in order to dry. L.A. abrasion loss was recorded as a difference between the original and the final mass. Low Los Angeles Abrasion loss values are desirable, since this indicates that an aggregate is tough and resistant to abrasion. SORB min. values for Los Angeles Abrasion loss should not exceed 45\%. Other agencies link the Los Angeles Abrasion value with rock source i.e. 10$20 \%$ for Basalt and 20-45\% for Granite which can be more accurate. 


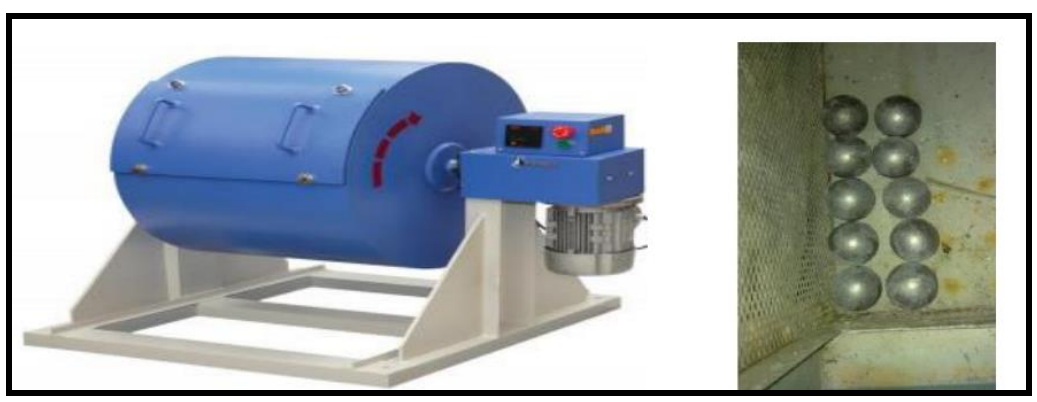

Fig. (4): Abrasion test (LA) Drum and Steel Balls

\subsubsection{Marshall Test}

Sample Preparation: Three types of aggregates were utilized in this study namely: gravel, limestone and crushed stone. The Method used for designing asphalt mixes was Marshall Mix design method. Each of the three types of aggregate were sieved and graded according to Iraqi SORB (2003), Aggregate blend samples were mixed with five different binder content ( $4 \%, 4.5 \%, 5 \%, 5.5 \%$ and $6 \%$ ), as per each binder content three samples were made. The binder and the aggregates were heated in the oven till $150 \mathrm{C}^{\circ}$. Afterwards, the binder were added to aggregates carefully on a balance, then the mixture was placed in a preheated mixing machine with heater is beneath the mixing bowl in order to keep the mixture hot during the mix, the mixing part was done by hand and a blade (manually) as depicted in Fig. (5). Then, it was placed in the Oven for $30 \mathrm{~min}$., next the mix sample was poured into a preheated cylindrical mould of $102 \mathrm{~mm}$ diameter and 64 $\mathrm{mm}$ height, after that the sample was compacted in the mould by applying 75 blows on each side.

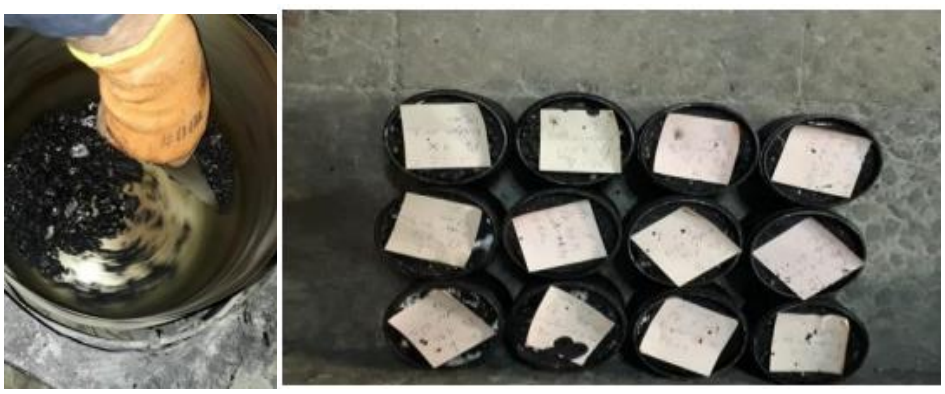

a) Mixing Manually

b) Samples after compaction

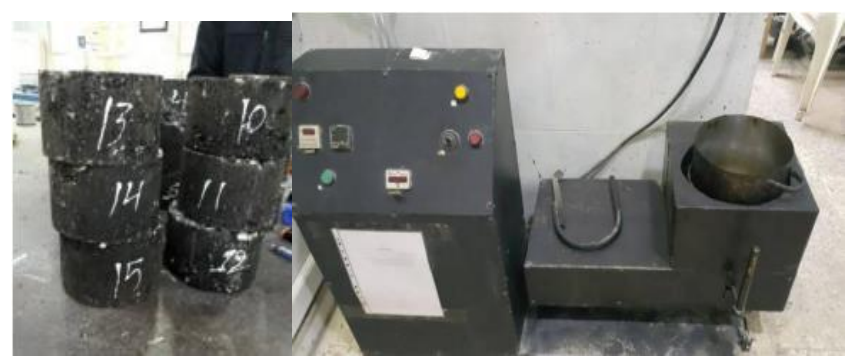

c) Samples after mould removal

d) Mixing Machine

Fig. (5): Marshall Test sample preparation and Mixing

Marshall Flow and Stability: The test was conducted as per ASTM D1559 (1976) specifications. The compacted HMA specimens were tested in Marshall Device (Fig. (6)) in order to determine their strength and deformation under load. The stability value was taken as the maximum load (in $\mathrm{kN}$ ) that the specimen can withstand, whereas, the flow was recorded as a value of maximum deformation in units of $0.25 \mathrm{~mm}$.

Marshall Property curves (air voids (VTM $\%)$, stability, Flow, Voids in mineral aggregates (VMA \%), and voids filled with aggregate (VFA $\%)$ ) were then used to calculate the Optimum Binder Content (OBC) of the mixes as shown in Fig.

(7). 


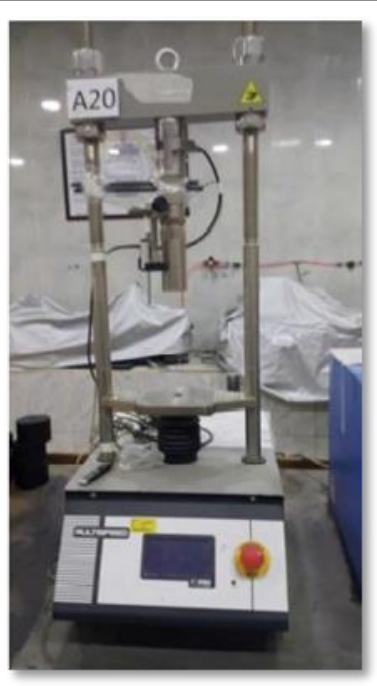

a) Marshall Device

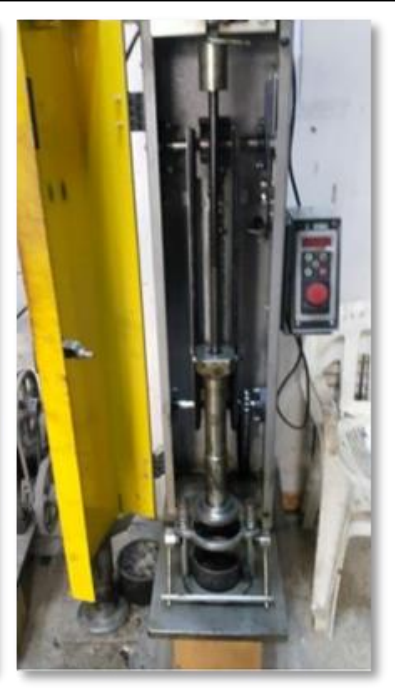

b) Marshall hammer

Fig. (6): Marshall Test Setup

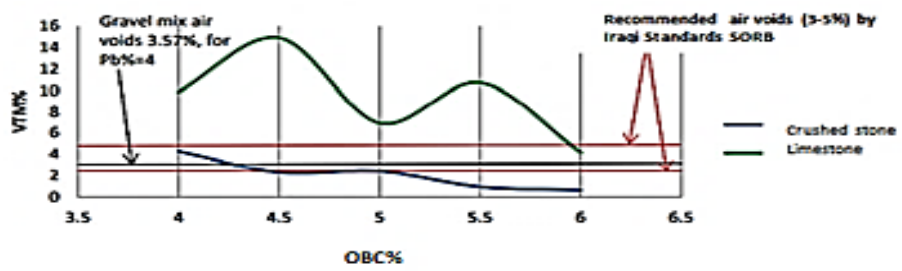

a)VTM Vs. OBC\%

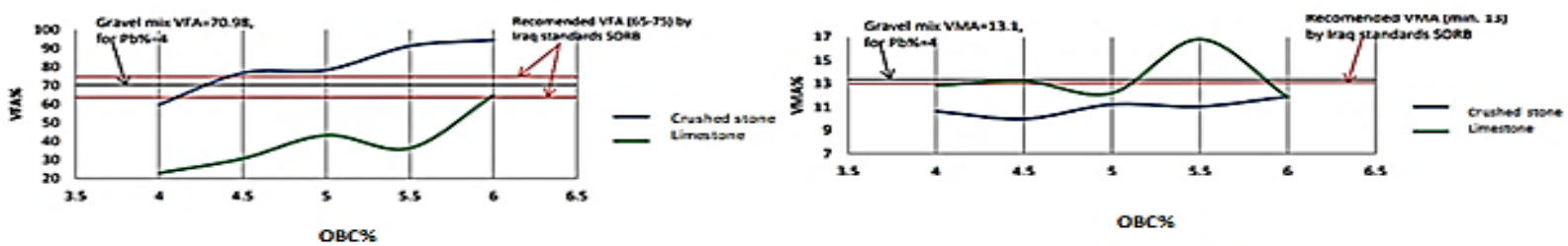

b) VFA Vs. OBCS

c) VMA Vs. OBCS

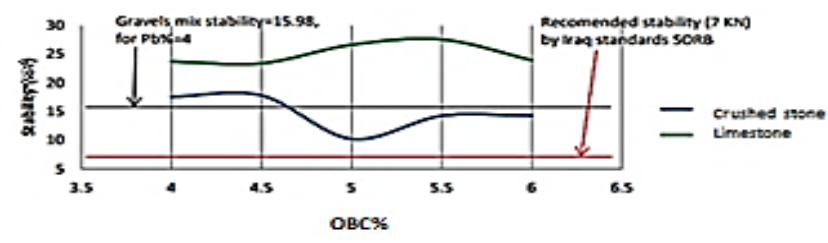

d) Stability Vs. OBC\%

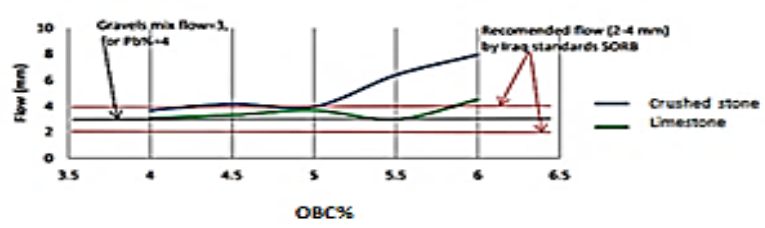

e) Flow Vs. OBC\%

Fig. (7): Marshal plots for finding $\mathrm{OBC}$ 


\section{RESULTS AND DISCUSSION}

\subsection{Specific gravity and absorption}

Table (3): Physical properties of coarse and fine aggregates

\begin{tabular}{|c|c|c|c|c|c|c|}
\hline \multirow[t]{2}{*}{ Property } & \multicolumn{3}{|c|}{ Coarse aggregate } & \multicolumn{3}{|c|}{ Fine aggregate } \\
\hline & Gravel & $\begin{array}{l}\text { Crushed } \\
\text { stone }\end{array}$ & Limestone & Gravel & $\begin{array}{l}\text { Crushed } \\
\text { stone }\end{array}$ & Limestone \\
\hline Bulk Specific gravity (GSb) (ASTM C 127,C128) & 2.647 & 2.674 & 2.583 & 2.612 & 2.575 & 2.335 \\
\hline Actual specific gravity(Gsa) (ASTM C 127,C128) & 2.717 & 2.759 & 2.733 & 2.732 & 2.765 & 2.700 \\
\hline $\begin{array}{l}\text { Water Absorption\% } \\
\text { (ASTM C 127,128-84) }\end{array}$ & 0.973 & 1.151 & 2.122 & 1.688 & 2.667 & 5.775 \\
\hline
\end{tabular}

\subsubsection{Specific gravity and absorption of coarse aggregates}

It can be seen in Table (3) that the specific gravity (bulk specific gravity Gsb and Actual specific gravity Gsa) of all three types of aggregates are within the ranges of (2.6 to 2.8 ), whereas the absorption of limestone seems to be considerably higher compared to the absorption of gravel and crushed stone. Moreover, this could be unsafe for the reason that the higher absorption causes a weak bond between aggregate and binder.

3.1.2. Specific gravity and absorption of fine aggregates

Table (3) shows that fine aggregate gravel has higher bulk specific gravity then followed by crushed stone and limestone, respectively. While crushed stone has higher actual specific gravity then comes gravel and limestone. Crushed stone absorbs more water inside its particles and not only on the surface as depicted from the table that the absorption of fine aggregate is substantially higher when compared to coarse aggregate absorption. This is due to the fact that as the material gets finer the surface that absorbs water increases hence resulting in the higher absorption value. Furthermore, the limestone absorbed the highest amount of water and that could cause difficulties during the freezing and thawing process. Whereas gravel resulted in the lowest value of absorption which was $71 \%$ lower than that of limestone.

\subsection{Los Angeles (L.A) Abrasion test results}

The results of abrasion test that carried out on three different types of aggregates are depicted in Fig. (8). All three types are within the specifications as their L.A. \% values do not exceed $45 \%$ as per SORB standards. Furthermore, limestone gave the higher L.A value of 35.48, than gravel and crushed stones of 20.72 and 22.16, respectively, which indicate that gravel and crushed stones have higher resistance to abrasion.

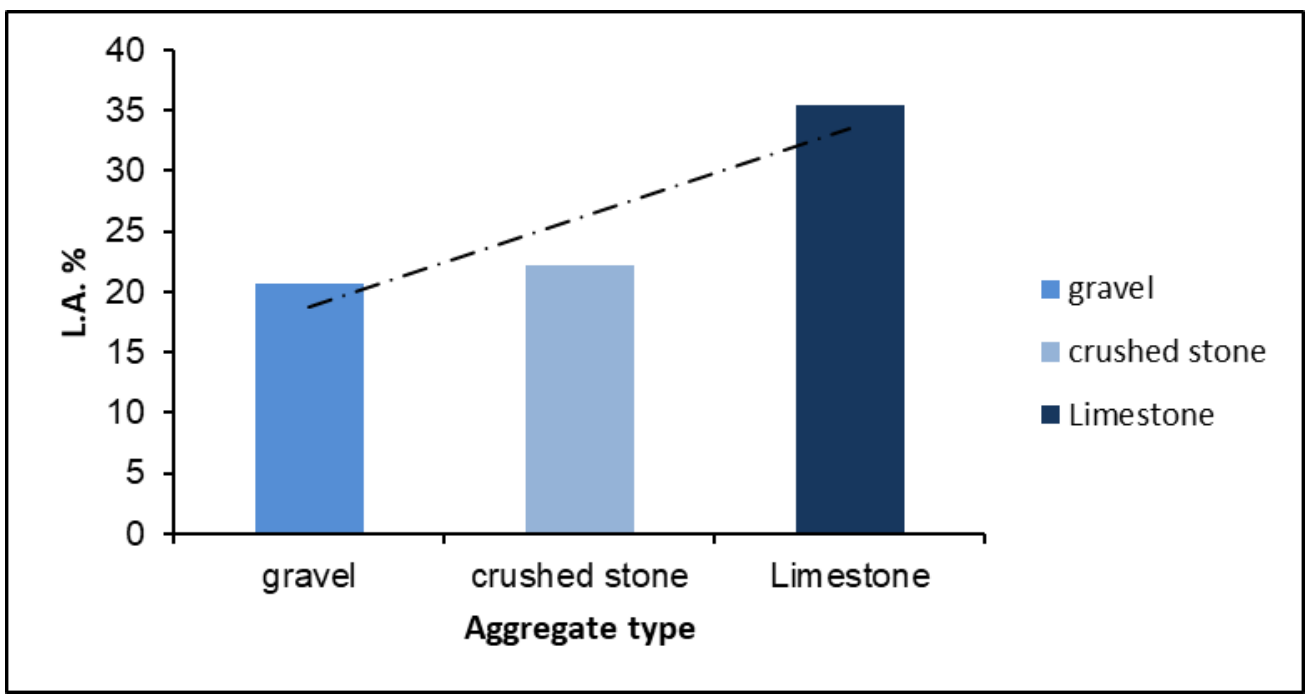

Fig. (8): Toughness (Abrasion) of three types of Aggregates used in this study 


\subsection{Marshall test results}

Iraqi SORB/2003 recommends 3-5\% air voids in the mix for pavements binder layer. Using The National Asphalt Pavement Association (NAPA) procedure for Marshall Design Method by depending on that taking 4\% as the best result (Von Quintus and Hughes, 2019). In Fig. (9) OBC\% (Optimum Binder Content) results for 4\% VTM shows that crushed stone with low percentage of binder has achieved the recommended air voids and with no significant difference to gravel, as crushed stones mix binder content is about $4.2 \%$ at $4 \%$ VTM. Limestone has achieved the recommended air voids at higher percentage of binder content, as it was about $6 \%$. As a result the use of crushed stone might be more economic than limestone. In addition, in Fig.(10), Pba (Amount of bitumen absorbed by aggregates) value shows that the absorbed binder by the limestone is higher than crushed stone and gravel, while Pbe(effective binder content) is the highest for gravel.

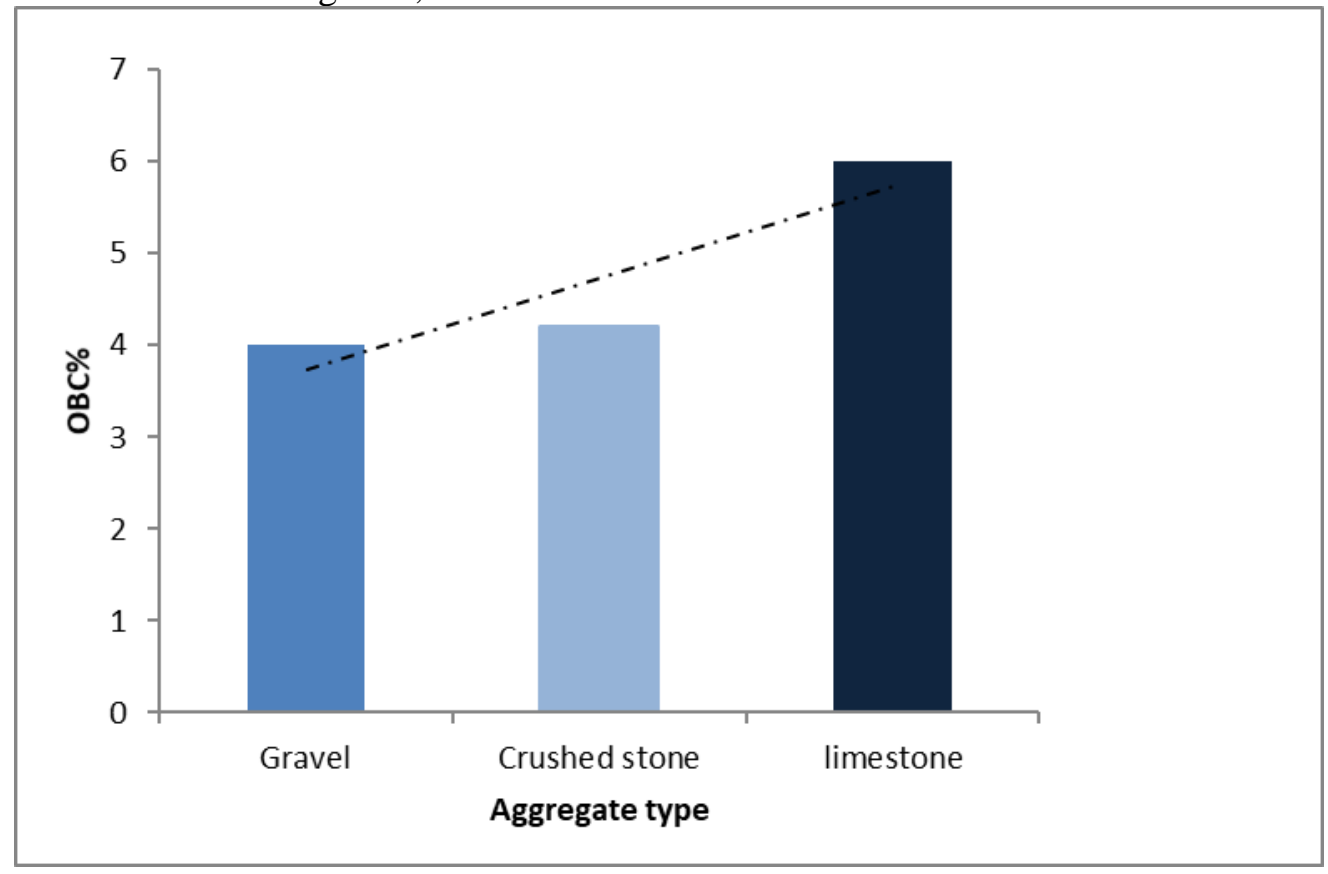

Fig. (9): Optimum Binder Content

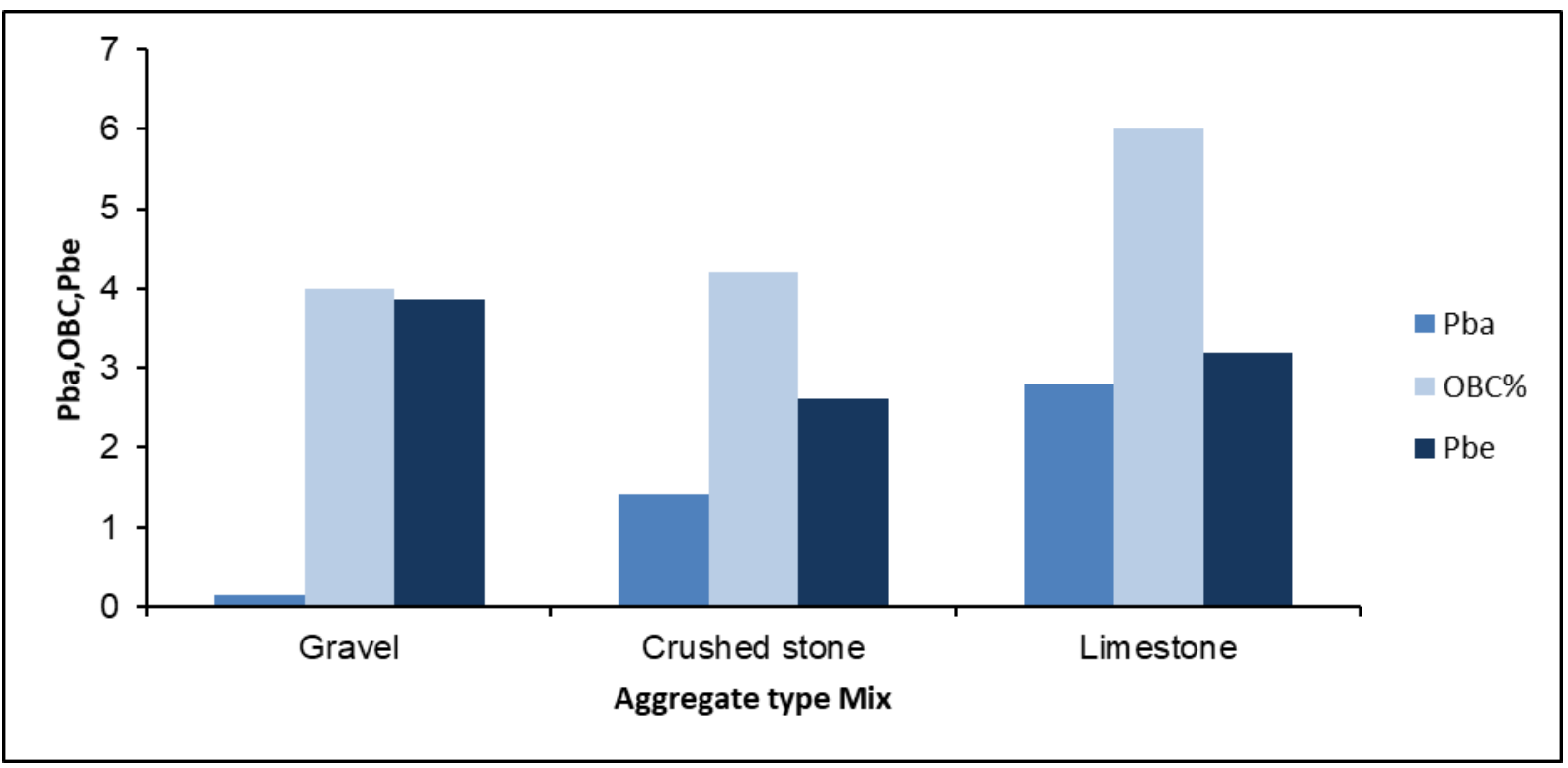

Fig. (10): Amount of Bitumen absorbed by Aggregates (Pba) and Effective binder content (Pbe) vs. Optimum Binder Content

sheyan.khaled@dpu.edu.krd; sundis.taher@uod.ac 
Fig. (11) presents stability results as Iraqi standard (SORB/2003) recommend $(7 \mathrm{KN})$ as a minimum stability for binder layer. It is obvious all three mixes are accepted for stability. Furthermore, the limestone stability is $37 \%$ higher than crushed stone and 50\% larger than gravel mix stability which may be due to less effective binder content. However as in previous calculations it turns out that crushed stone might be a better exchange for gravel, so the accepted stability will be enough to consider crushed stone as a better alternative to gravel than limestone, and for that as both mixes are accepted yet crushed stone may be better as it has less binder content.
Fig. (12) shows Flow results, it appears that for crushed stones mix with $4.2 \%$ binder content, flow value is about $3.6 \mathrm{~mm}$ and it fits in the recommended range of flow $2-4 \mathrm{~mm}$ by SORB/2003 Iraqi standard, while for the limestone mix with $6 \%$ binder content, flow value is about $4.4 \mathrm{~mm}$ which is not accepted. Therefore crushed stone again takes an advantage over limestone as an alternative to gravel, as high flow value of limestone mix could be susceptible to rutting and deformation. Moreover, the gravel mix flow value showed a value of about $3.1 \mathrm{~mm}$ which is not much different from crushed stone mix flow value.

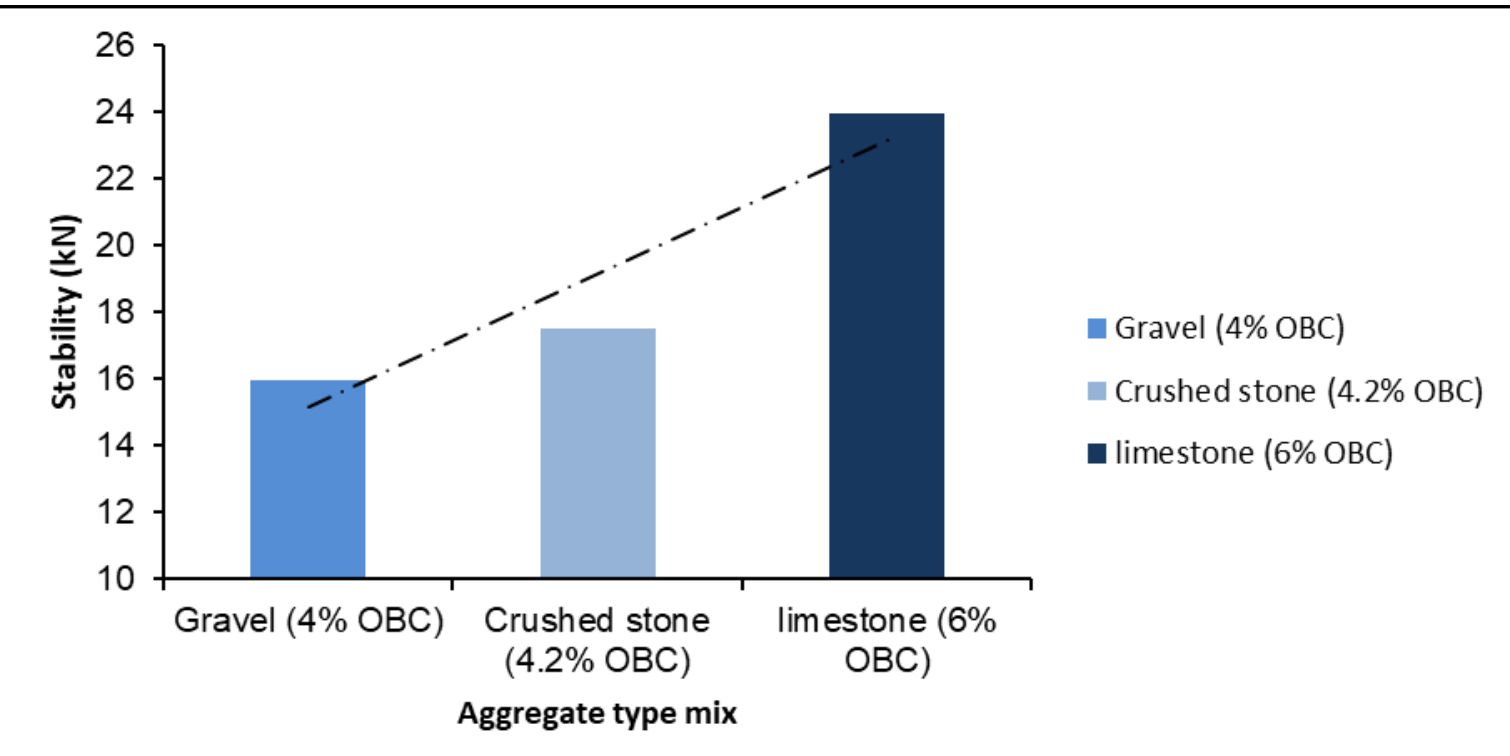

Fig. (11): The Impact of Aggregate Type on Stability

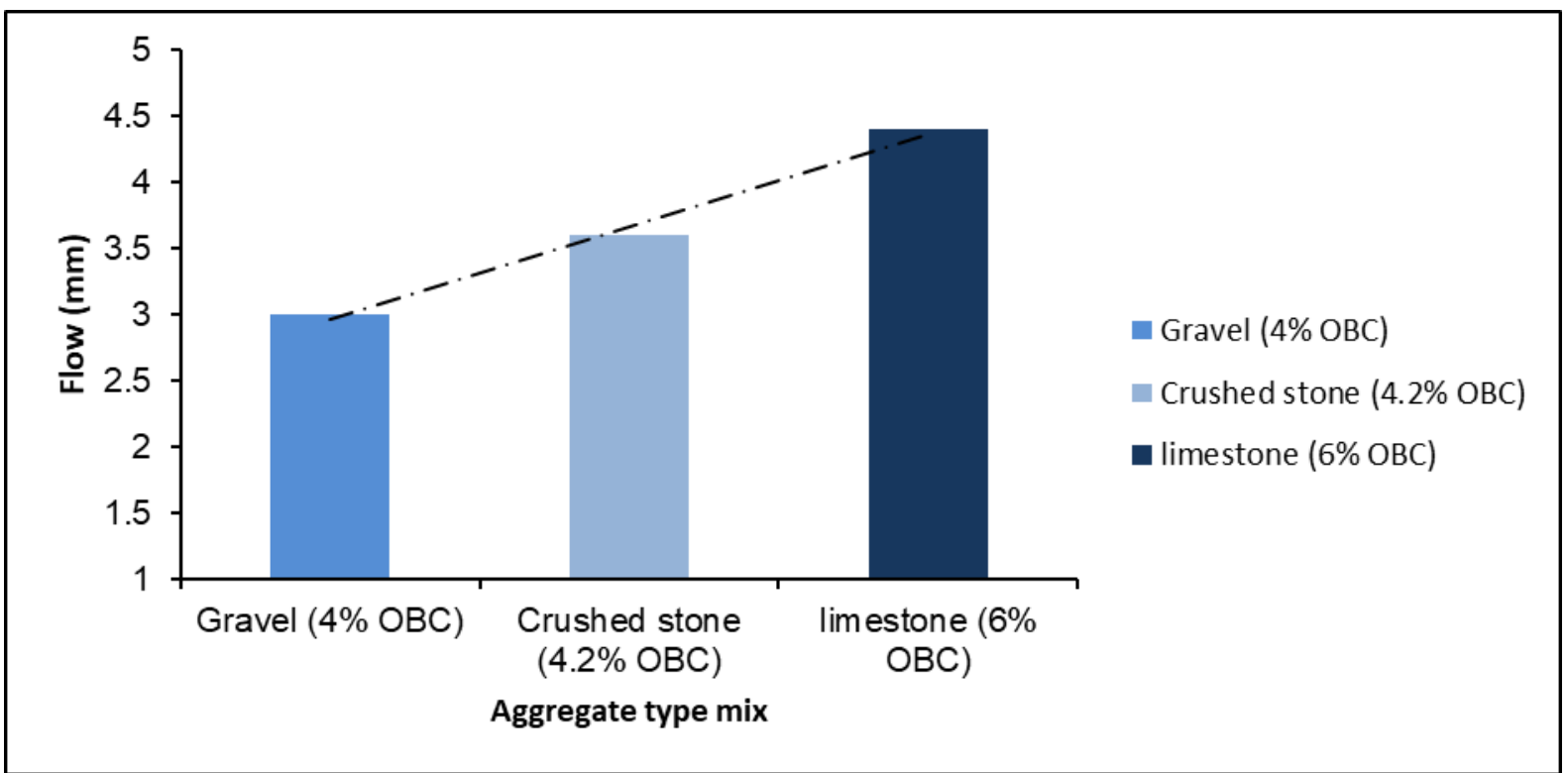

Fig. (12): The Flow property of all Types of Aggregates used in HMA mix sheyan.khaled@dpu.edu.krd; sundis.taher@uod.ac 
Fig. (13) shows that for $4.2 \%$ binder content of crushed stone VMA value is about 10\% which is not within the accepted range as Iraqi standard, (SORB/2003) recommends 13\% VMA as a minimum value for pavements binder layer. similarly limestone with $6 \%$ binder content gives VMA value of about $12 \%$ which is not accepted either, while the value of $13.3 \%$ was resulted by gravel which is an acceptable value. This issue can be solved by trying more gradations within the specified limits.

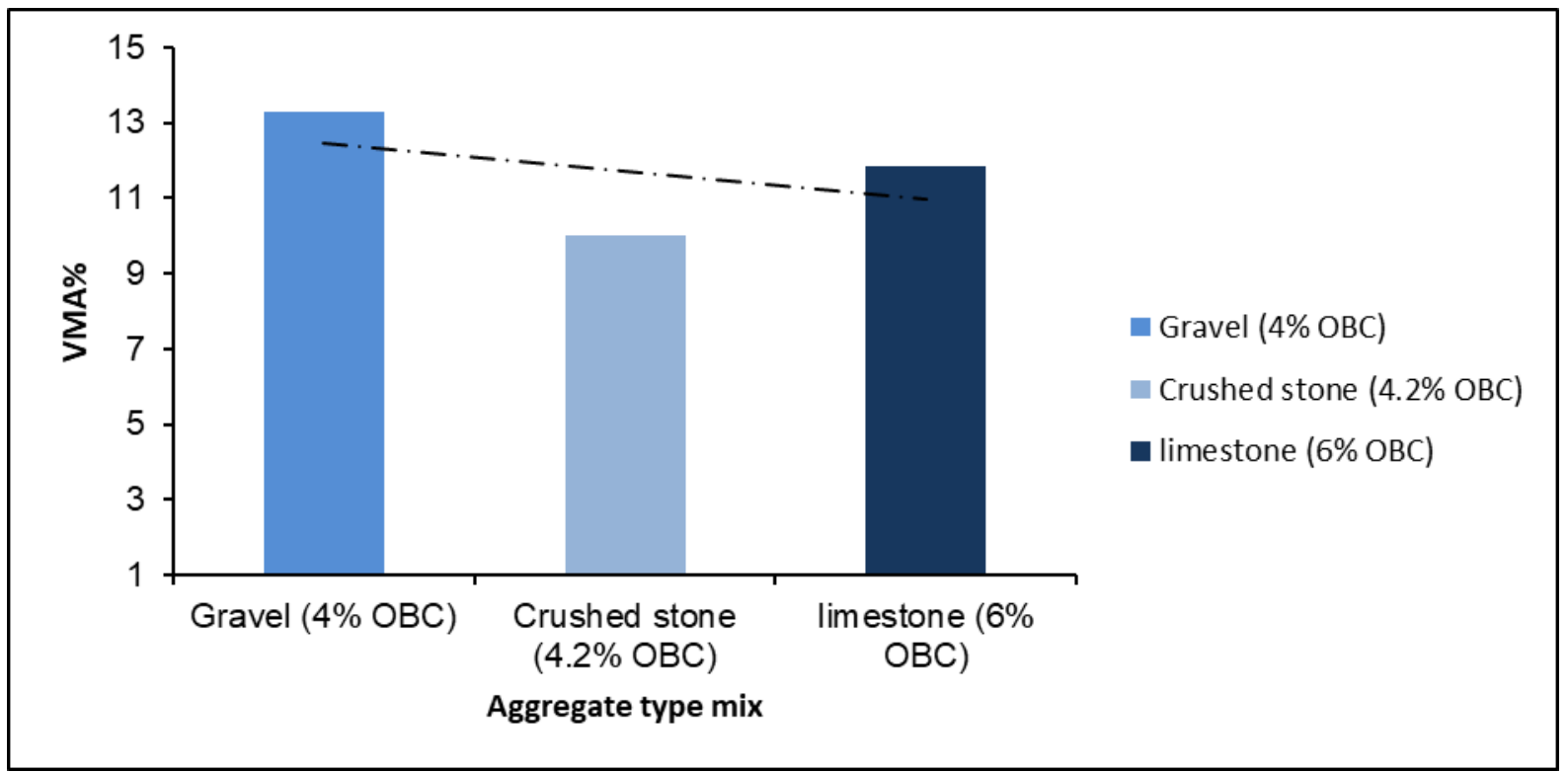

Fig. (13): The Voids in Mineral Aggregate for for all three mixes

The Iraqi standard (SORB/2003) recommends $65-75 \%$ VFA as range for pavements binder layer. VFA\% results are depicted in Fig. (14) It can be seen from the figure that for $4.2 \%$ binder content of crushed stone mix the value of VFA is about $67 \%$, and the limestone mix gives the value of $66 \%$, while, gravel mix recorded a VFA value of $71 \%$ which is also an acceptable value.

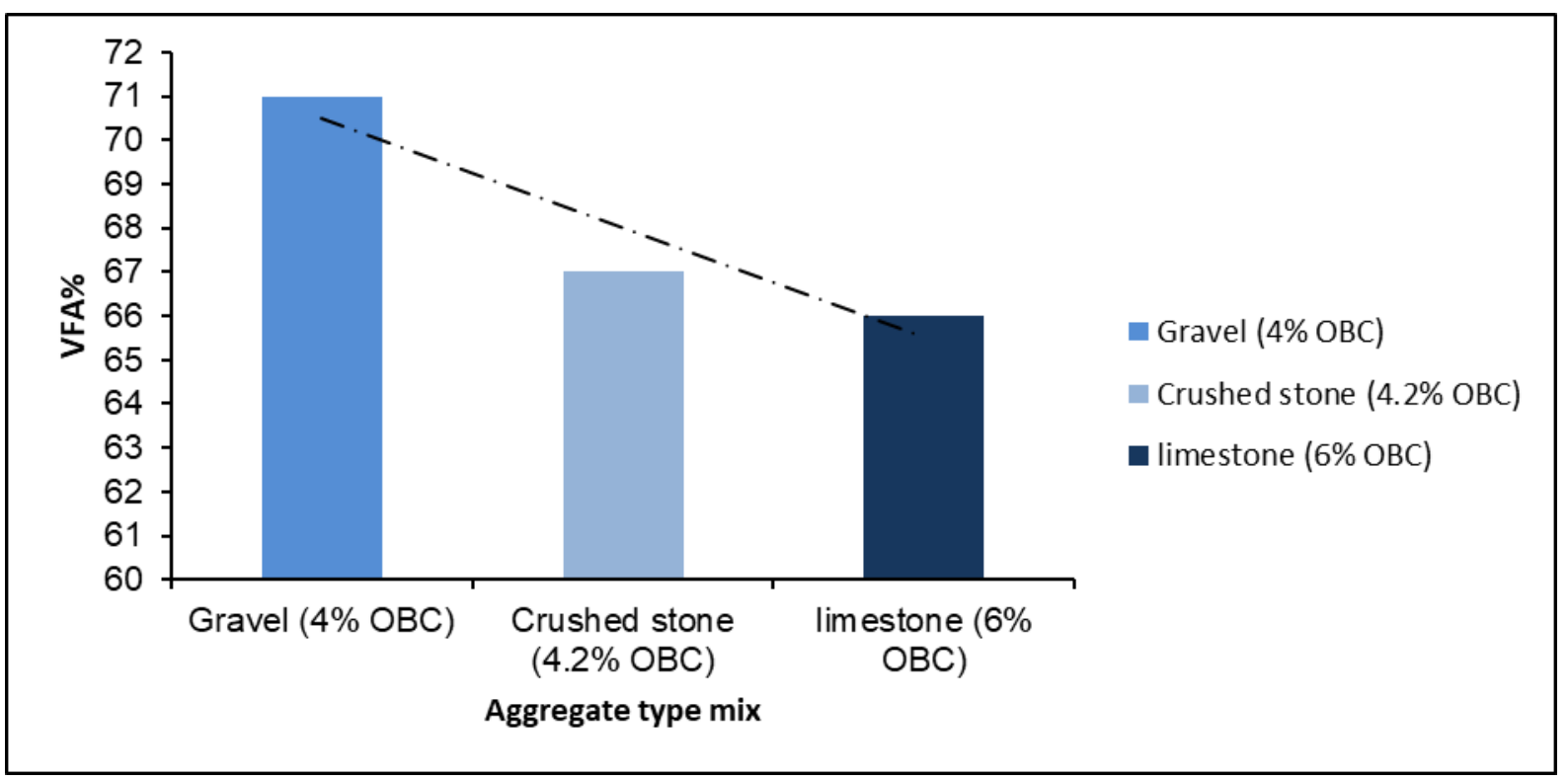

Fig. (14): The Percentage of Voids Filled with Asphalt for all three mixes 


\section{CONCLUSION}

This study evaluated the influence of aggregate type and characteristics on properties of hot-mix asphalt. Furthermore, the characteristics of three types of aggregates were examined in L. A. abrasion and specific gravity tests. The following conclusions were drawn based on the experimental data:

1- The bulk specific gravity of coarse aggregates was the highest for crushed stone followed by gravel while for fine aggregate and aggregate blend gravel recorded the highest value of Gsb, additionally; crushed stone gave the highest actual specific gravity in both fine and coarse aggregates. Likewise, the absorption of limestone was extremely high when compared to gravel and crushed stone absorption in fine and coarse aggregates.

2- The abrasion test results showed that gravel and crushed stone are tougher than limestone since gravel recorded the lowest abrasion value of $20.72 \%$ then followed by crushed stone of $22.16 \%$ value, and limestone of $35.48 \%$ abrasion.

3- The optimum binder content was found to be the maximum for limestone and the minimum value was achieved by gravel which was less than that of limestone by 33\%. Whereas crushed stone gave a value close to gravel Optimum binder content.

4- All three types of aggregates gave the higher stability value than the minimum acceptable value recommended by SORB/2003, with limestone giving the highest value.

5- Flow results showed that gravel and crushed stone flow values are accepted while limestone flow is not acceptable according to $\mathrm{SORB} / 2003$.

6- Percent voids filled in aggregates VFA\% values for all three types were within the recommended range of $65-75 \%$. Whereas VMA\% values for both limestone and crushed stone were out of the recommended range by SORB for pavement binder layers. This issue can be solved by trying more gradations within the specified limits.

To sum up it can be seen from the results shown in this study that gravel remains the best aggregate for HMA, while crushed stone might be accepted in some occasions as an alternative to gravel.

\section{ACKNOWLEDGMENT}

The authors acknowledge the support of Duhok Construction Lab and Duhok Road and Bridge Directorate.

\section{REFERENCES}

AASHTO T96 (2002) 'Standard Method of Test for Resistance to Degradation of Small-Size Coarse Aggregate by Abrasion and Impact in the Los Angeles Machine'.

Abo-Qudais, S. and Al-Shweily, H. (2007) 'Effect of aggregate properties on asphalt mixtures stripping and creep behavior', Construction and Building Materials, 21(9), pp. 1886-1898. doi: 10.1016/j.conbuildmat.2005.07.014.

Ahmed, H. Y. et al. (2014) 'Investigation of aggregate particles shape', Journal of Engineering Sciences Faculty of Engineering, 42, pp. 1349-1366.

Ahmed, M. A. and Attia, M. I. E. (2013) 'Impact of Aggregate Gradation and Type on Hot Mix Asphalt Rutting In Egypt', International Journal of Engineering Research and Applications (IJERA), 3(4), pp. 2249-2258.

Al-Humeidawi, B. H. (2016) 'Experimental Characterization of Rutting Performance of HMA Designed with Aggregate Gradations According to Superpave and Marshall Methods', World Journal of Engineering and Technology, 04(03), pp. 477-487. doi: 10.4236/wjet.2016.43048.

Al-Saadi, A. H., Al-Kafaji, M. K. A. and AlMaimuri, N. M. L. (2011) 'Evaluation of using a white gravel of Kerbala quarries in asphalt mixes', Al-Taqani, 24(3), pp. 117-127.

ASTM C 127, Specific Gravity and Absorption of Coarse Aggregates, ASTM C 128, Specific Gravity and Absorption of Fine Aggregates, Annual Book of ASTM Standards, vol. 04.02, ASTM, Philadelphia, 1999

ASTM C131-01 (2001) 'Standard Test Method for Resistance to Degradation of Small-Size Coarse Aggregate by Abrasion and Impact in the Los Angeles Machine'. ASTM International, West Conshohocken, PA.

ASTM D1559 (1976) 'Resistence to Plastic Flow of Bituminous Mixtures Using Marshall Apparatus', Annual Book of ASTM Standards, pp. $1-5$.

Cui, S. et al. (2014) 'Durability of asphalt mixtures: Effect of aggregate type and adhesion promoters', International Journal of Adhesion and Adhesives, 54, pp. 100-111. doi: 10.1016/j.ijadhadh.2014.05.009.

Dai, Q. (2010) 'Prediction of dynamic modulus and phase angle of stone-based composites using a micromechanical finite-element approach', 
Journal of materials in civil engineering, 22(6), pp. 618-627.

Jitsangiam, P., Chindaprasirt, P. and Nikraz, H. (2013) 'An evaluation of the suitability of SUPERPAVE and Marshall asphalt mix designs as they relate to Thailand's climatic conditions', Construction and Building Materials, 40, pp. 961-970. doi: 10.1016/j.conbuildmat.2012.11.011.

Kalaitzaki, E., Kollaros, G. and Athanasopoulou, A. (2016) 'Influence of aggregate gradation on hma mixes stability', Romanian Journal of Transport Infrastructure, 4(2), pp. 13-22. doi: 10.1515/rjti-2015-0034.

Mahmoud, A. A. H. (2014) 'Effect of Aggregate Gradation and Type on hot asphalt concrete mix properties', Journal of Engineering Sciences Assiut University Faculty of Engineering, 42(4), pp. 567-574.

Pandit, A., Mistry, R. and Roy, T. K. (2019) 'Effect of aggregate type on Marshall properties of bituminous mix containing fly ash as filler', AIP Conference Proceedings, 2158(September). doi: 10.1063/1.5127146.

Prowell, B. D., Zhang, J. and Brown, E. R. (2005) Aggregate properties and the performance of superpave-designed hot mix asphalt. Transportation Research Board.

Von Quintus, H. L., \& Hughes, C. S. (2019) Design \& Construction of Heavy-Duty Pavements. Second edi. Lanham, Maryland National Asphalt Pavement Association.

Sissakian, V. (2019) 'Quarries and the Environment in the Kurdistan Region, Iraq', UKH Journal of Science and Engineering, 3(2), pp. 52-60. doi: 10.25079/ukhjse.v3n2y2019.pp52-60.
SORB (State Corporation for Roads and Bridges) (2003) General Specification for Roads and Bridges (SORB/R9)-Hot Mix Asphaltic Concrete Pavement. Edited by A. N. . Editor. Revised Edition. Baghdad: Department of Planning and Studies, Republic of Iraq, Ministry of Housing and Construction,.

Weyers, R. E. et al. (2005) 'Testing Methods to Determine Long Term Durability of Wisconsin Aggregate Resources', (October), p. 91.

Williams, S. G. and Cunningham, J. B. (2012) 'Evaluation of Aggregate Durability Performance Test Procedures: Final Report TRC-0905', p. 77.

Wu, Y., Parker, F. and Kandhal, P. S. (1998) 'Aggregate toughness/abrasion resistance and durability/soundness tests related to asphalt concrete performance in pavements', Transportation Research Record, (1638), pp. 85-93. doi: 10.3141/1638-10. 